Fund, made an intensive study of sub-cultures of the Patayan culture, excavating a site seven miles north of Williams, Arizona, which consisted of a large masonry fort and seventeen earth lodge sites. A preliminary conclusion, pending further analyses, establishes the existence of the Cohonina Branch of the Patayan culture, differing essentially from the Hohokam of the south and the Pueblo to the east. A relationship to the people of the Colorado to the west is suggested.

The Cohonina lived a semi-sedentary life, part agricultural, part food-gathering. Their homes were surface structures built of perishable material, earth lodges, of which the detailed architecture is difficult to trace. Much charcoal was collected, which, however, has as yet yielded no dendrochronological evidence. Ceramic types date occupation at about A.D. 700 and A.D. 1100, the fort with its massive masonry belonging to the later period of occupation. A special projectile point was used to which the name "Cohonina point" has been given. Few ornaments were used, none of shell. The pottery belongs to the San Francisco mountain gray ware; and from its distribution it is possible to fix the extension of the Cohonina Branch-the area between the Little Colorado River on the east and the escarpment of the plateau on the west, and from the Grand Canyon on the north to the San Francisco volcanic field in the south.

An investigation of primitive Indian agriculture in the south-west by Edward F. Castetter, of the University of New Mexico, throws light on the crops grown anciently in this region. A preliminary survey was made of the technique, crops and implements among Mohave, Yuma, Cocopa, Maricopa, Papago, Pima, and a number of Pueblo groups. The ancient crops were maize, beans, pumpkins, cotton, tobacco and gourd. In addition, the Colorado River tribes sowed several species of grasses. The Pueblo peoples had a much greater variety of corn and beans than the peoples of the Gila and Colorado Rivers, who had only four-yellow, blue, white and speckled, all corn of the flour type. The pumpkins were Cucurbita moschata. It was found that agriculture could not be investigated adequately without knowledge of ritual, the two being inseparable; but it was difficult to obtain information owing to the secrecy of the Indians, especially the Pueblo, on such matters.

\title{
BIOLOGY AND SYSTEMATICS OF THE SARGASSUM WEED
}

$\mathrm{M}^{\mathrm{A}}$ ATERIAL for research on the floating Sargassum vegetation of the western North Atlantic was collected in connexion with a series of hydrographic cruises to the central American seas on the research ship Atlantis, sponsored jointly by the Woods Hole Oceanographic Institution and by Yale University (under the auspices of the Bingham Oceanographic Foundation), a special surface net being used which was designed to gather floating weeds from the sea surface on a quantitative basis, and the results of the researches have now been published*.

This net has been in actual operation on the surface of the Sargasso Sea and of the central American seas for a total cumulative towing length of nearly 7,000 nautical miles, and as a result of this towing more than 4,700 pounds of pelagic weeds have been sorted and weighed on board. Experimental evidence shows that these weeds do not occur in any quantity at any significant distance below the surface.

In the taxonomic discussion a key is given for the identification of the main types of floating Sargassum weed, illustrated by a number of silhouettes. The author concludes that the fixed, more or less distinct, external forms in which the truly pelagic weeds occur represent only phenotypic variations of not more than two separate species, $S$. natans and $S$. fluitans. Even the distinctness of these two species, although probable, is not established entirely without doubt.

The quantitative estimates show that floating weed is scarce in the Caribbean and Cayman Seas and practically absent from the entire southern half of the Caribbean itself, whilst in the north-western region of the Gulf of Mexico a secondary accumulation

* "Quantitative Observations on the Pelagic Sargassum Vegetation of the Western North Atlantic. With Preliminary Discussion of Morphology and Relationships"'. By Albert Eide Parr. Bull. Bingham Oceanographic Collection, Peabody Museum of Natural History, Yale University, 6, Art. 7. Dec. 1939. of apparently deteriorating weeds in considerable abundance was observed over a wide area. The chief region for thriving pelagic weeds was entirely outside the central American seas in that part of the North Atlantic designated as the Sargasso Sea.

The distribution, as shown in these results, confirms the previous hydrographic conclusions, that the failure of the drifting flora to penetrate northward across the Caribbean agrees with the assumption that the Caribbean surface water is mainly derived from the south-east via the north equatorial current and not from the Sargasso Sea itself. The accumulation of floating weed in the north-western part of the Gulf of Mexico must be interpreted as a result of pure wind drift, due to prevailing easterly winds moving the weeds in relation to the water; this accumulation could scarcely take place in the presence of a significant tendency to outward movement of the surface water towards the Straits of Florida.

Up to the present time, no benthonic fixed stage is known of the two species $S$. natans and S. fuitans, and it has been a controversial subject as to whether these weeds grow vegetatively to any great extent in the floating state. Recent authorities increasingly favour the theory that such growth does take place, and the present work shows conclusively that these weeds grow and prosper for years without any sexual reproduction; and further, there can be no conceivable source and process of annual renewal of pelagic Sargassum vegetation from benthonic flora which could possibly maintain the floating vegetation in its observed abundance with an average duration of the pelagic state of the individual plants to be reckoned in less than decades. One fertile plant attached to a drifting piece of wood was obtained which was otherwise indistinguishable from sterile representatives of the pelagic $S$. fluitans, the only 
one ever found and of great importance in showing the form of the sexual phase, as it will now be possible to search for a known fixed form.

It is thus firmly maintained, supporting Winge (1923) and others, that "the pelagic Sargassum of the Sargasso Sea, apart from its marginal zones, is probably an essentially self-sustaining unit with a potentially infinite longevity and a very long normal expectancy of life for its individual plants, receiving (at most) only a very slight annual contribution from benthonic vegetation merely sufficient to compensate for its own loss by a slight excess of mortality over vegetative growth increment, suffered mainly through a continually occurring chance return of some of its members to the dangerous marginal zones from which a corresponding recruitment of freshly de. tached plants which have escaped its hazards are received in exchange."

The significant fact remains that no fixed benthonic stage is yet known of either of the two predominant types of floating Sargassum weed of the Sargasso Sea, namely, $S$. natans and $S$. fluitans. It seems that it must be concluded that here we have an essentially self-sustaining community of plants in which the pelagic existence has become secondarily normal, and which are able to maintain and multiply themselves indefinitely by mere vegetative growth, mechanical fragmentation and irregular partition of the individuals through disintegration from the basal end.

\section{RECENT AMERICAN INVESTIGATIONS IN EMBRYOLOGY}

$\mathrm{A}^{\mathrm{N}}$ $\mathrm{N}$ interesting paper of practical importance in orthopædic practice, entitled "The Functional Results of Muscle Transposition in the Hind Limb of the Rat", was read by Prof. R. W. Sperry at the Columbus Meeting of the American Association last December. The muscles operating the hind foot of this animal were transplanted in reverse, with the result that both reflex and voluntary movements of the hind limb were also reversed. Motion pictures showed that even after a year's trial of the new arrangement, there was no adjustment, and although the muscles worked the limb, the motor nerve patterns for limb co-ordination were on the old basis. Unfortunately the author does not state the names or number of the transplants.

Papers on experimental embryology related to the early development of the sea urchin, Arbacia punctulata. Profs. W. C. Allee and Asher J. Finkel, starting from the observed acceleration in cleavage-rate due to density of egg population and suspecting that some growth-promoting substance was responsible, carried out a series of experiments at Woods Hole with the intention of finding out more about the stimulating factor. They did not succeed in determining the chemical nature of the substance or substances; but their experiments showed that an extract from Arbacia eggs, even in "extremely dilute concentrations, can accelerate the early development of Arbacia eggs to a significant degree over that of untreated but otherwise similar eggs". They suggest that "undercrowding is as real in its effects as over. crowding".

Miss Ethel Browne Harvey studied the role of the nucleus and the cytoplasm in Arbacia eggs. Unfertilized eggs, broken into half eggs by centrifugal force, give a nucleated and a non-nucleated half. Both halves can be fertilized, or activated artificially. In the former case two plutei are produced; in the latter, the nucleated half becomes a pluteus, the nonnucleated half a blastula only. Fertilized eggs behave differently. A half containing both pronuclei forms a blastula, or at most a defective pluteus. A nonnucleated half, although its cytoplasm is affected by fertilization, does not even cleave, but the cytoplasm may make an attempt to produce asters.

The author calls the development of the nonnucleated half of the artificially activated but unfertilized egg "parthenogenetic merogony". But since this half develops to the blastula stage only, it would appear that a nucleus is essential for the differentiation of the cells, though not for their mere multiplication.

Prof. Robert Chambers and E. L. Chambers found that fertilization of the egg in Arbacia could be arrested by immersing the egg immediately after insemination in a solution of potassium chloride, the strength of which is not stated. The return of the eggs so treated to normal sea-water more than an hour later causes resumption of activity of the sperm and subsequent normal development.

Two papers on transplantation of embryonic limb buds in birds were read by Prof. H. L. Eastlick. In the first set of experiments the chick embryo was the host, and duck, chukar partridge, quail, guinea fowl and turkey were the donors of the grafts. Both leg and wing were employed, transplantation being effected on embryos two to three days old. The egg was then re-sealed and put back in the incubator for further development. Fifteen per cent of the embryos hatched with the graft as a fifth limb. These grafts retained the structural characters of the donor species, except in a few cases where a partial merging of skin characters of donor and host occurred. Thus a duck leg graft formed a webbed foot, the feathers of which failed to develop after a poor attempt to do so ; they were followed by a second growth of host feathers. In other cases the graft limb grew at first but was later resorbed.

According to a second paper the birds mentioned above were used as hosts, but did not prove as successful for this purpose as the chick. Although the graft retained many of the characters of the parent bird, the age and extent of the graft affected the result. In particular, a graft removed with a portion of the neural crest developed feathers of the same colour as the graft's parent, whereas a graft cut laterally so as not to include the neural crest partook of the colour characters of the host. Grafts from white silky bantams, the feathers of which have no hooklets on the barbules, retained this character when transplanted to White Leghorn or Barred Plymouth Rock hosts. Prof. Eastlick described and illustrated some of his results in a brief communication published in Nature of August 26, 1939, p. 380. 